\title{
Tiotropio efektyvumas gydant LOPL per Respimat Soft Mist inhaliatoriu
}

Reikšminiai žodžiai: anticholinerginis vaistas, lètinè obstrukcinė plaučių liga, inhaliatorius, tiotropis, Respimat.

Santrauka. Tiotropis, anticholinerginis vaistas, inhaliuojamas vieną kartą per dieną naudojant HandiHaler ${ }^{\oplus}$, išplečia bronchus ilgiau nei 24 valandoms ir taip pagerina pacientų savijautą. Respimat Soft Mist ${ }^{T M}$ (SMI) inhaliatorius - tai naujas propelento neturintis inhaliatorius, sukurtas gydyti tiotropiu kaip alternatyvus inhaliatorius. Spiriva ${ }^{\oplus}$ Respimat $^{\oplus}$ išpurškiamas unikalus lėtai judantis drėgnas vaisto srautas SMI užtikrina, kad Spiriva ${ }^{\circledR}$ geriausiai patektų i plaučius, todèl daugumai sergančiuju lètine obstrukcine plaučių liga (LOPL) jỉ naudoti paprasta ir paranku.

\section{SVARBIAUSIOS RESPIMAT ${ }^{\circ}$ SAVYBĖS}

Didelis efektyvumas. Ilgai veikiantis drègnas vaisto srautas išpurškiamas daug lèčiau nei aerozolio debesèlis iš dozuoto aerozolinio inhaliatoriaus (DAI), taigi vaisto mažiau nusèda burnoje ir ryklejje, palyginti su DAI. Dèl to paprasčiau įkvejpti i plaučius, t. y. pacientui nereikia koordinuoti kvejpavimo su vaisto įkvejpi$\mathrm{mu}$, kai vaisto veikimo nauda yra didžiausia pacientui. Plaučiu scintigrafiniai tyrimai parodè, kad, naudojant Respimat $^{\circ}$, i plaučius patenka daug daugiau veikliosios medžiagos negu naudojant kitos rūšies aerozolinius inhaliatorius (pav.)
Dozavimas. SPIRIVA ${ }^{\circ}$ Respimat $^{\circ} 5 \mu \mathrm{g}$ paros dozè, vartojama vieną kartą per dieną dviem ịpurškimais po $2,5 \mu \mathrm{g}$, terapiniu požiūriu lygi SPIRIVA ${ }^{\circ}$ HandiHaler $^{\circ}$ $18 \mu \mathrm{g}$ poveikiui.

Irodymais pagrịstas LOPL gydymas. J. A. van Noord su bendradarbiais atliko tyrimą, kuriuo vertino tiotropio, vartojamo per Respimat ${ }^{\circ}$ ir HandiHaler ${ }^{\circ}$ inhaliatorius, efektyvumą gydant LOPL sergančius pacientus. Tai buvo dviejų identišku 30 savaičių trukmès daugiacentrių atsitiktinių imčių placebu kontroliuojamų dvigubai aklų tyrimu analizė [1-14]. Tyrimo tikslas ivertinti tiotropio efektyvumą ir toleravimą LOPL sergantiems pacientams vaistą skiriant per Respimat $^{\circ} S M I$

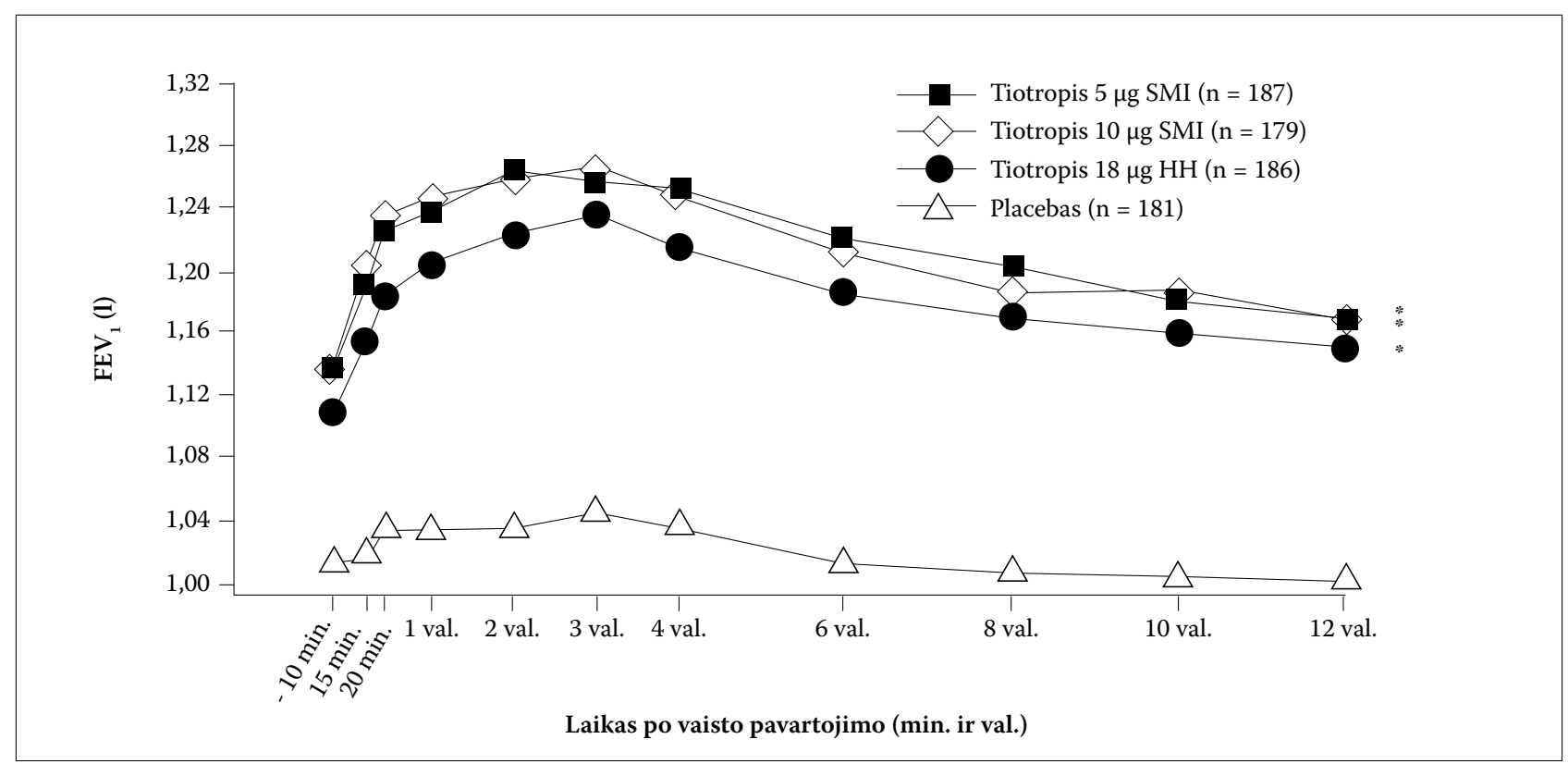

Pav. Vidutinis FEV 1 pokytis 29-tą dieną vartojant $5 \mu \mathrm{g}$ ir $10 \mu \mathrm{g}$ tiotropio per Respimat SoftMist (SMI), 18 mg tiotropio per HandiHaler (HH) inhaliatorių ir placebą 
(5 $\mu \mathrm{g}$ ar $10 \mu \mathrm{g}$ tiotropio) ir per HandiHaler ${ }^{\circ}$ inhaliatorių $(18 \mu \mathrm{g})$. Tyrime dalyvavo 207 pacientai, kurių 72 proc. sudarè vyrai, 62 proc. metusieji rūkyti, LOPL sergantys daugiau kaip 10 metu, vidutinis $\mathrm{FEV}_{1}$ buvo 37 proc. būtinojo dydžio. Skiriant tiotropi $5 \mu \mathrm{g}$ ir $10 \mu \mathrm{g}$ dozèmis per Respimat SMI ženkliai pagerejo $\mathrm{FEV}_{1}$ rodiklis, lyginant su placebu, ir efektas nebuvo silpnesnis nei skiriant $18 \mu \mathrm{g}$ tiotropio per HandiHaler. Tyrimas įrodè, jog 29-tą dieną vidutinis $\mathrm{FEV}_{1}$ rodiklis vartojant $5 \mu \mathrm{g}$ tiotropio per Respimat $S M I$ buvo didesnis $29 \mathrm{ml}$ ( $\mathrm{p}<0,03)$, vartojant $10 \mu \mathrm{g}$ - didesnis $31 \mathrm{ml}$ $(\mathrm{p}<0,02)$ nei vartojant $18 \mu \mathrm{g}$ tiotropio per HandiHaler. Terapinis vaisto poveikis, kuri rode daugiau kaip 15 proc. nuo pradinio per 2 valandas po pirmosios vaisto dozès padidejęs $\mathrm{FEV}_{1}$, naudojant Respimat SMI pirmą dieną pasireiškè 64 proc. pacientų $5 \mu \mathrm{g}$ tiotropio grupejje ir 72 proc. - $10 \mu \mathrm{g}$ tiotropio grupèje, palyginti su 57 proc. pacientu $18 \mu \mathrm{g}$ tiotropio, vartojamo per HandiHaler, grupeje ir 22 proc. - placebo grupejje. Gydant bet kuria tiotropio doze pirmą ir 29-tą diena buvo ženkliai pagerinti spirometrijos rodikliai $\left(\mathrm{FEV}_{1}\right.$ pikas, FVC pikas, bei FEV ir FVC pokytis $0-12$ val. po tiotropio inhaliacijos). Visi šie rodikliai pagerejo lyginant $5 \mu \mathrm{g}$ ir $10 \mu \mathrm{g}$ SMI su $18 \mu \mathrm{g}$ HandiHaler.

Dažniausi nepageidaujami reiškiniai, kurie nustatyti 3 proc. pacientų, buvo LOPL paūmejjimas (9,8 proc. $5 \mu \mathrm{g}, 10,9$ proc. $-10 \mu \mathrm{g}, 11,2$ proc. $-18 \mu \mathrm{g}$ tiotopio bei 13 proc. - placebo grupèse) ir nazofaringitas $(7,5$ proc. $-5 \mu \mathrm{g}, 8,2$ proc. $-10 \mu \mathrm{g}, 5,9$ proc. $-18 \mu \mathrm{g}$ tiotropio bei 8,2 proc. placebo grupèse).

Gauti rezultatai rodo, jog per Respimat SMI inhaliatoriu $5 \mu \mathrm{g}$ ir $10 \mu \mathrm{g}$ dozemis vartojamas tiotropis $\mathrm{FEV}_{1}$ pagerina ne prasčiau kaip $18 \mu \mathrm{g}$ tiotropio dozé ( $\mathrm{p}<0,0001)$. Dar daugiau - 29-tą dieną $5 \mu \mathrm{g}$ ir $10 \mu \mathrm{g}$ tiotropio grupése $\mathrm{FEV}_{1}$ buvo apie $30 \mathrm{ml}$ didesnis nei 18 $\mu \mathrm{g}$ tiotropio grupeje. Abu inhaliatoriai greitai pagerino plaučių funkciją ir pagerèjusią išlaikè net 12 valandų po vaisto issipurškimo. Pogrupių farmakokinetinė analizè įrodè, jog sisteminis vaisto poveikis vartojant 5 $\mu \mathrm{g}$ tiotropio per Respimat SMI ir $18 \mu \mathrm{g}$ tiotropio per HandiHaler yra panašus, o didžiausia vaisto koncentracija susidaro skiriant $10 \mu \mathrm{g}$ tiotropio per Respimat $S M I$. Tai irodo, jog $5 \mu \mathrm{g}$ tiotropio skiriant per Respimat SMI susidaranti sistemine vaisto koncentracija ir poveikis plaučių funkcijai yra panašūs kaip vartojant $18 \mu \mathrm{g}$ per HandiHaler. $5 \mu \mathrm{g}$ Respimat SMI grupeje nepageidaujami reiškiniai buvo tokie patys kaip $18 \mu \mathrm{g}$ HandiHaler.

Išvada. Tyrimas ịrodè, kad pacientams, sergantiems LOPL (nuo vidutinio sunkumo iki labai sunkios), tiotropis, vartojamas per Respimat SMI, pagerina plaučiu funkciją bei yra puikiai toleruojamas, palyginti su tiotropiu, vartojamu per HandiHaler, ir placebu [13, 25]. Veiksminga vaisto koncentracija, susidaranti vartojant $5 \mu \mathrm{g}$ tiotropio per Respimat SMI, buvo tokia pati kaip vartojant $18 \mu \mathrm{g}$ tiotropio per HandiHaler, vadinasi, gydant mažesnėmis dozèmis gydymo efektyvumas nė kiek nesumažès, o saugumas bus daug didesnis.

\section{EFFICACY OF TIOTROPIUM IN THE TREATMENT OF COPD}

Keywords: anticholinergic, chronic obstructive pulmonary disease, inhalation therapy, tiotropium, Respimat ${ }^{\oplus}$

Summary. Tiotropium, a once daily inhaled anticholinergic delivered via HandiHaler ${ }^{\oplus}$, provides bronchodilation for $>24 \mathrm{~h}$ and improves patient-centred outcomes. The Respimat ${ }^{\oplus}$ SoftMist Inhaler ${ }^{\circledast}$ (SMI), a novel, propellant-free inhaler, has been developed and proposed as an alternative delivery device for use with tiotropium.

Parengè M. Vaitkus

\section{LITERATŪRA}

1. Dalby R, Spallek M, Voshaar T. A review of the development of Respimat Soft Mist Inhaler. Int J Pharm. 2004;283:1-9.

2. Zierenberg B. Optimizing the in vitro performance of Respimat. J Aerosol Med. 1999;12(Suppl. 1):S19-S24.

3. Hill LS, Slater AL. A comparison of the performance of two modern multidose dry powder asthma inhalers. Respir Med. 1998;92:105-110.

4. Rau JL. The inhalation of drugs: advantages and problems. Respir Care. 2005;50:367-382.

5. Vincken W. Clinical efficacy and safety of the combination of ipratropium bromide and fenoterol inhaled via the Respimat ${ }^{\oplus}$ Soft Mist $^{\mathrm{TM}}$ inhaler for relief of airflow obstruction. Expert Rev Resp Med. 2008;2:11-26.

6. Vincken W, Bantje T, Middle MV, Gerken F, Moonen D. Long-term efficacy and safety of ipratropium bromide plus fenoterol via Respimat ${ }^{\oplus}$ Soft Mist $^{\mathrm{TM}}$ Inhaler (SMI) versus a pressurized metered-dose inhaler in asthma. Clin Drug Investig. 2004;24:17-28.

7. Casaburi R, Mahler DA, Jones PW, et al. A long-term evaluation of oncedaily inhaled tiotropium in chronic obstructive pulmonary disease. Eur Respir J. 2002;19:217-224.

8. Vincken W, van Noord JA, Greefhorst APM, et al. Improved health outcomes in patients with COPD during 1 yr's treatment with tiotropium. Eur Respir J. 2002;19:209-216.

9. Donohue JF, van Noord JA, Bateman ED, et al. A 6-month, placebo-controlled study comparing lung function and health status changes in COPD patients treated with tiotropium or salmeterol. Chest. 2002;122:47-55.

10. Niewoehner DE, Rice $K$, Cote $C$, et al. Prevention of exacerbations of chronic obstructive pulmonary disease with tiotropium, a once-daily inhaled anticholinergic bronchodilator: a randomized trial. Ann Intern Med. 2005;143:317-326.

11. Brusasco V, Hodder R, Miravitlles M, Korducki L, Towse L, Kesten S. Health outcomes following treatment for six months with once daily tiotropium compared with twice daily salmeterol in patients with COPD. Thorax. 2003;58:399-404.

12. Okudan N, Gök M, Gökbel H, Süerdem M. Single dose of tiotropium improves the 6-minute walk distance in chronic obstructive pulmonary disease. Lung. 2006;184:201-204.

13. Caillaud D, Le Merre C, Martinat Y, Aguilaniu B, Pavia D. A dose-ranging study of tiotropium delivered via Respimat ${ }^{\circledR}$ Soft Mist ${ }^{\mathrm{TM}}$ Inhaler or HandiHaler $^{\ominus}$ in COPD patients. Int J Chron Obstruct Pulmon Dis. 2007;2:1-7.

14. van Noord JA, Cornelissen PJG, Aumann J-L, et al. Efficacy in COPD patients of tiotropium administered via Respimat ${ }^{\oplus}$ Soft Mist $^{\mathrm{TM}}$ Inhaler (SMI) compared to HandiHaler ${ }^{\otimes}(\mathrm{HH})$. Eur Respir J. 2006;28(Suppl. 150):431.

15. Quanjer PH, Tammeling GJ, Cotes JE, et al. Lung volumes and forced ventilatory flows. Report working party standardization of lung function tests, European Community for Steel and Coal. Official Statement of the European Respiratory Society. Eur Respir J Suppl. 1993;16:85-100.

16. American Thoracic Society . Standardization of spirometry: 1994 update. Am J Respir Crit Care Med. 1995;152:1107-1136. 